\title{
LA BUENA ADMINISTRACIÓN PÚBLICA EN EL SIGLO XXI: ANÁLISIS DEL CASO COLOMBIANO
}

Diana Carolina Valencia-Tello

Profesora Principal de Derecho Administrativo de la Universidad del Rosario (Bogotá, Colombia). Especialista en Derecho Administrativo y Derecho Ambiental de la Universidad del Rosario. Maestría, Doctorado y Post-Doctorado de la Universidad Federal del Paraná (Brasil). E-mail: dianac.valencia@urosario.edu.co

Daniel Wunder Hachem

Profesor de Derecho Constitucional y Derecho Administrativo de la Pontificia Universidad Católica de del Paraná y de la Universidad Federal del Paraná (Curitiba-PR, Brasil). Doctorado y Maestría en Derecho de la Universidad Federal del Paraná. Post-Doctorado de la Université Paris

1 Panthéon-Sorbonne (Francia). Consejero Directivo de la Red Docente Eurolatinoamericana de Derecho Administrativo. Director del NUPED - Núcleo de Pesquisas em Políticas Públicas e Desenvolvimento Humano de la PUCPR. Abogado.

E-mail: danielhachem@gmail.com

\section{RESUMEN}

El artículo tiene el objetivo de identificar el significado del concepto de buena Administración Pública en el siglo XXI y sus impactos en el Derecho Administrativo, con destaque para el caso colombiano. El trabajo realiza algunas precisiones sobre los orígenes del Derecho Administrativo en el Estado liberal, para luego contrastar estas características con el Derecho Administrativo y la buena Administración Pública en el Estado Constitucional y Democrático de Derecho del siglo XXI. Hace una presentación del contenido jurídico del derecho fundamental a una buena Administración Pública y sus principales características de acuerdo con la doctrina y los principales documentos jurídicos que tratan del tema, como la Carta Iberoamericana de los Derechos y Deberes del Ciudadano en relación con la Administración Pública de 2013 y la Carta Europea de Derechos Fundamentales de 2000. Finalmente, el artículo describe cómo se aplica en concreto este nuevo concepto en Colombia, relatando algunas experiencias adoptadas en ese país con el objetivo de mejorar la calidad de la gestión pública.

Palabras-clave: buena administración pública; siglo XXI; transformaciones del Derecho Administrativo; derechos fundamentales; Derecho Administrativo colombiano. 
THE GOOD PUBLIC ADMINISTRATION IN THE XXI CENTURY: ANALYSIS OF THE COLOMBIAN CASE

\begin{abstract}
The article aims to identify the meaning of the concept of good Public Administration in the 21st century and its impact on Administrative Law, with emphasis on the Colombian case. The paper makes some precisions on the origins of Administrative Law in the liberal State, to then contrast these characteristics with Administrative Law and good Public Administration in the constitutional and democratic rule of law of the 21st century. It makes a presentation of the legal content of the fundamental right to a good Public Administration and its main characteristics in accordance with the scholarship and the main legal documents dealing with the subject, such as the Ibero-American Charter of the Rights and Duties of the Citizen in relation to Public Administration of 2013 and the European Charter of Fundamental Rights of 2000. Finally, the article describes how this new concept is applied in Colombia, reporting some experiences adopted in that country with the aim of improving the quality of public management.
\end{abstract}

Keywords: good public administration; XXI century; transformations of Administrative Law; fundamental rights; Colombian Administrative Law. 


\section{INTRODUCCIÓN}

En la actualidad, el derecho a la buena administración es un concepto que cada vez adquiere más relevancia en razón a la necesaria transformación que debe tener la administración pública para mejorar su relación con la ciudadania y entregar mejores bienes y servicios, que promuevan el interés general de las comunidades. El concepto no es nuevo, pues desde siempre, en teoría, la Administración Pública ha tenido por objetivo la promoción del interés general de todos los ciudadanos. Pero en el siglo XXI, el derecho a la buena administración adquiere nuevas conotaciones, en razón a la necesidad de fortalecer los procesos democráticos en todos los Estados, mejorando la participación de la ciudadanía y la rendición de cuentas, junto a la protección de los derechos fundamentales de todos los individuos, en un mundo globalizado e interconectado.

Aquí es importante anotar que desde el inicio del Estado moderno, el Derecho Administrativo ha sido una de las principales herramientas con la que cuentan gobernantes y gobernados al momento de materializar las formas de gobierno establecidas en la Constitución y las leyes (KRISTJÁNSDÓTTIR, 2013, p. 237-255). La forma como se materializan estos postulados generales cambia en cada época, dependiendo de múltiples variables históricas y culturales que condicionan las interpretaciones de los funcionarios públicos y de los ciudadanos.

En este orden de ideas, el derecho a la buena administración representa un "novedoso derecho-garantía de última generación" (CARRILLO DONAIRE, 2010, p. 1152), el cual busca hacer explícita la coherencia que debe existir entre la Constitución y el ordenamiento interno, en Estados Democraticos y Sociales de Derecho, con la finalidad de impactar positivamente la relación entre el Estado y los particulares.

A simple vista, este novedoso derecho puede parecer más de lo mismo, pero como bien lo señala el Profesor Jaime Rodríguez-Arana (2013), subrayar la importancia de la buena Administración hace referencia al contraste que existe con la experiencia previa de Administraciones Públicas que no han servido al pueblo, ni lo han hecho objetivamente atendiendo el interés general.

Así, teniendo en cuenta el contraste señalado por el Profesor Rodríguez-Arana, ${ }^{1}$ el presente artículo pretende contrastar los fundamentos

1 Para una visión profundizada del pensamiento del autor sobre el tema, véase: RODRÍGUEZ-ARANA 
de la buena Administración pública en el inicio del Estado moderno, frente a lo que se entiende hoy en día como buena Administración pública en el siglo XXI.

Para desarrollar este análisis comparativo, a continuación el trabajo va a realizar algunas precisiones sobre los orígenes del Derecho Administrativo en el Estado liberal, para luego contrastar estas características con el Derecho Administrativo y la buena administración pública en el Estado Constitucional y Democrático de Derecho. En la siguiente sección serán presentadas algunas precisiones sobre las nociones generales de buena Administración Pública en el siglo XXI. Posteriormente, serán analizadas las principales características que debe tener la buena Administración Pública, para luego describir cómo se aplica en concreto este nuevo concepto en Colombia. En la conclusión serán presentadas algunas consideraciones para futuras investigaciones.

\section{ORÍGENES DEL DERECHO ADMINISTRATIVO EN EL ESTADO LIBERAL}

La consolidación del Estado moderno fue un largo proceso que requirió de varios siglos de luchas y de alianzas entre nobres y burgueses para centralizar el poder, declarando también la autonomía del monarca frente a la iglesia. Esto porque la Edad Media se caracterizó por la dispersión del poder en diversas autoridades, causando la existencia de diversos cuerpos normativos, jurisdicciones y cortes con diversos grados de legitimidad en las comunidades (TAMANAHA, 2008, p. 375-411). Para centralizar todo el poder en cabeza del Estado, dos aspectos fundamentales deben ser resaltados aquí: el primero es la centralización de la facultad de hacer las leyes en el Estado, y el segundo, no menos importante, es la consolidación de un aparato administrativo que representa al Estado y que tiene por objetivo hacer cumplir la ley, recaudar impuestos, juzgar, entre otros.

Para Weber (2012, p. 78-79), una de las principales caracteristicas del Estado moderno es que institucionaliza un nuevo tipo de dominación legal que descansa en la validez de un Derecho, establecido racionalmente, de forma tal que los miembros de la organización cuando obedecen al jefe "no obedecen a su persona sino al ordenamiento impersonal, y por

MUÑOZ, 2012a; RODRÍGUEZ-ARANA MUÑOZ, 2012b; RODRÍGUEZ-ARANA MUÑOZ, 2012c; RODRÍGUEZ-ARANA MUÑOZ, 2010; RODRÍGUEZ-ARANA MUÑOZ, 2007. 
lo tanto sólo están obligados a prestar obediencia dentro del ámbito de las competencias objetivas delimitadas racionalmente por el ordenamiento".

En este sentido, el inicio del Estado moderno se caracteriza por la racionalización del poder, el cual facilitó la ampliación de las estructuras administrativas según el modelo jerárquico y centralizado (que es una herencia del antiguo régimen monárquico), reforzando poco a poco las técnicas administrativas y ampliando el poder de las burocracias, conforme las necesidades del momento (RODRIGUEZ-ARANA, 2009, p. 33). En esta época, la imperiosa necesidad de orden y seguridad jurídica ayudó a consolidar las estructuras administrativas bajo la clave de unicidad de comando (BOBBIO et al, 2010, p. 430), con funcionarios capaces de establecer la última decisión de forma unidireccional, esto es, sin permitir mayor participación de la ciudadanía. Al respecto, Alexis de Tocqueville (2010) en su libro sobre el Antiguo Régimen y la Revolución afirma: "admito que la centralización es una gran conquista y estoy de acuerdo en que Europa nos envidia, pero sostengo que no es en absoluto una conquista de la Revolución. Es, por el contrario, un producto del Antiguo Régimen, y añadiré también que es lo único de la constitución política del Antiguo Régimen que ha sobrevivido a la Revolución, porque era lo único que podía acomodarse al nuevo estado social que esta Revolución creó".

En consecuencia, en esta etapa inicial del Estado, la buena Administración está relacionada a la centralización del poder, mediante la existencia de un cuerpo administrativo con capacidad de cumplir y hacer cumplir la ley para garantizar el orden y la seguridad jurídica que requerían las comunidades; en donde una de las prioridades era evitar a toda costa el irrespeto a los principios de libertad e igualdad de todos los ciudadanos, proclamados por la Revolución, en aras de terminar con los antiguos privilegios de los nobles bajo el Antiguo Régimen.

Por ello, Giannini (2010, p. 67) afirma que, desde un punto de vista político, el Derecho Administrativo nasce vinculado al autoritarismo porque el carácter autoritario de la acción administrativa en relación con los ciudadanos es una técnica jurídica que nasció por razones políticas en el Estado burgués. Es importante, sin embargo, percibir que si la realidad política antes y después de la Revolución Francesa era igualmente autoritaria, esto no significa que siguió siendo autoritaria de la misma forma. $^{2}$

El carácter autoritario del Derecho Administrativo va a

2 Sobre el tema, véase: GABARDO; HACHEM, 2010. 
manifestarse de forma más clara en la Europa Continental del siglo XIX, pues los discursos sobre los derechos y las libertades se basan más sobre el Estado y su derecho que sobre la Constitución y los derechos fundamentales de los ciudadanos (FIORAVANTI, 2007, p. 108), llevando a que la limitación del Estado por el Derecho se confunda con el imperio de la ley creado por el Parlamento. En este contexto, hablar de la centralidad de la dignidad del ser humano para justificar las decisiones de la Administración Pública es toda una utopía.

Así, una buena Administración pública es aquella que garantiza una dominación racional mediante una organización continua y reglada por cargos oficiales, la cual no solo debe garantizar la formación especializada del funcionario público para desempeñar el cargo, sino que adicionalmente debe delimitar objetivamente las esferas de competencia, determinando la distribución de obligaciones y la jerarquía de los cargos para efectos de ejercer controles y supervisión efectiva sobre las actividades realizadas por todo el aparato burocrático (WEBER, 2012, p. 79-81).

Bajo la perspectiva racional, el Derecho que rige el Estado se construye con base en la gran dicotomía entre lo público y lo privado; entre iguales y desiguales. Así, el Estado, representado por su Administración Pública se caracteriza por mantener relaciones desiguales, esto es, relaciones de subordinación entre gobernantes y gobernados, entre quien tiene el poder de mandar y quien tiene el deber de obedecer (BOBBIO, 1989, p. 15.).

En este orden de ideas, el Derecho Administrativo visto como Derecho de Estado es creado con base en la idea de superioridad del Estado y su poder soberano sobre la sociedad. En contraposición al Estado se presentan las relaciones en la sociedad (sociedad natural conforme es descrita por los ius-naturalistas, o sociedad de mercado en la idealización de los economistas clásicos), las cuales se caracterizan por pertenecer a la esfera privada, y, por lo tanto, son relaciones entre iguales o de coordinación; son relaciones reguladas por el Código Civil, como Derecho fundamentado en la igualdad de los individuos pertenecientes a la sociedad (RODRIGUEZ-ARANA MUÑOZ, 2009, p. 16).

El Derecho Administrativo como Derecho positivo del Estado, basado en la ideología del estatismo liberal, aunque no sea un Derecho codificado (como el Derecho Civil), es un Derecho creado como un sistema cerrado y autosuficiente, dotado de propias y especificas instituciones y principios generales elaborados por la ciencia jurídica. El Derecho 
Administrativo existe porque la Administración Pública ${ }^{3}$ necesita de un Derecho propio y específico basado en la potestad soberana del Estado del nivel más alto que el Derecho de la sociedad civil. Por esto, no se puede admitir que el Estado como Administración se someta con su autoridad a un régimen jurídico civil ordinario (FIORAVANTI, 2007, p. 111).

Adicionalmente, la creación de un sistema cerrado y autosuficiente, especial para la Administración Pública, aseguraba que la Administración estaría siempre subordinada a la ley, y por lo tanto, todos los actos cumplirían con el principio de legalidad, fundamental para tutelar los derechos de los ciudadanos sin necesidad de apelar a los jueces. De esta forma se consideraba que la aplicación de la norma a la realidad era un procedimiento automático, es decir, libre de toda valoración subjetiva o política por parte del funcionario público competente.

Para Weil (1977, p. 12-13), al establecer el principio de separación de poderes entre las autoridades administrativas y judiciales, ${ }^{4}$ se buscaba impedir a los tribunales que perturbaran la Administración y, para esto, en esta primera etapa del Estado liberal, se prohibió el conocimiento de litigios en donde la Administración Pública era parte. El poder judicial, cuya misión natural era dirimir los litigios declarando el derecho, salía debilitado y disminuido, ya que el recelo de perturbar las operaciones de los cuerpos administrativos era tal que el propio juez administrativo evitaba contrariar a la Administración. Así, un poder judicial incapaz de juzgar a la Administración es un poder judicial que no cuenta con autonomía e independencia para la protección de los derechos fundamentales de los ciudadanos.

De esta forma el Derecho Administrativo se convierte en Derecho positivo del Estado, el cual representa la autoridad misma del Estado, lo que se realiza colocando el núcleo del poder público soberano en el Estado, esto es, más allá de la Constitución, en una zona que no puede ni debe ser alcanzada por los individuos. Aún así este poder del Estado se entiende como no arbitrario, en razón a que es un poder normalizado que pretende generar normas aplicables a todos, buscando seguridad jurídica tanto dentro de la sociedad como dentro de las estructuras administrativas, mediante la certeza del derecho (FIORAVANTI, 2007, p. 111-112). En el

\footnotetext{
3 Aquí la Administración Pública es comprendida en su sentido más amplio, esto es, como el cuerpo encargado de desarrollar el conjunto de actividades directamente designadas a la ejecución concreta de tareas consideradas de interés público o común, en una colectividad u organización estatal. BOBBIO et al, 2012, p. 10.

4 Sobre el tema, véase: CORVALÁN, 2015, p. 225-256.
} 
Estado Liberal de Derecho, la Administración Pública tiene una función marginal y subsidiaria, aunque para muchos teóricos ella ejerce un papel insustituible de puente entre la sociedad y el Estado (BOBBIO et al, 2012, p. 431).

Para Pietro Costa (2008, p. 66), la construcción del Estado como un aparato de comando durante la época de policía permitió mantener al Estado alejado de la sociedad, aunque aparentemente se buscaba informar y fomentar el desarrollo. Por esto, el Estado y la sociedad son dimensiones opuestas, en donde la maquina del Príncipe persigue la realización de valores propios que no coinciden con los de la sociedad que comanda.

La doctrina más madura del Estado de Derecho afirmará que los derechos de los individuos se fundan sobre un acto soberano de autolimitación del Estado, ya que si las libertades se fundamentan en las normas del Estado, se debe admitir que existe un derecho fundamental de ser tratado conforme las leyes del Estado (FIORAVANTI, 2007, p. 118$120)$.

La justicia administrativa es un remedio poco efectivo contra los actos arbitrarios de la Administración Pública, ${ }^{5}$ pues ésta fue proyectada y estructurada para no comprometer el principio básico de la soberanía del Estado, ya que la Administración no podía ser implicada en un juicio entre pares como cualquier particular. Así, en un sistema político fundado sobre principios de carácter estatalista, es difícil que el juez sea completamente libre para tutelar los derechos individuales en momentos en que choca con las razones de la autoridad. El juez no se fundamenta en la Constitución al momento de juzgar, sino en la expresión de soberanía del Estado, de forma tal que no puede ser un tercero neutral (FIORAVANTI, 2007, p. 120). Como bien lo puntualiza Rodríguez-Arana (2009, p. 23), "el Derecho Administrativo se concebía en función de la propia Administración Pública y al amparo de la necesaria estabilidad de buenas leyes".

\section{EL DERECHO ADMINISTRATIVO Y LA BUENA ADMINISTRACIÓNPÚBLICAENELESTADOCONSTITUCIONAL Y DEMOCRÁTICO DE DERECHO}

Para Giannini, hacia finales del siglo XIX el Estado liberal entra en crisis, debido principalmente a que los derechos políticos debieron ser 5 Actualmente, sin embargo, los modelos de justicia administrativa han experimentado muchas transformaciones y avances. En este sentido, véase: PERLINGEIRO, 2017, p. 167-205; ASIMOW, 2017, p. 129-165; CANE, 2017, p. 77-110. 
reconocidos a estratos más amplios de ciudadanos, de forma tal que cuando se impone el sufragio universal, cambia el tipo sociológico del Estado. Así, de un Estado de clase única se pasó a un Estado de pluralidad de clases, pero este cambio no fue percibido por la ciencia jurídica de la época, lo que se demuestra al verificar que las Constituciones en casi todas partes continuaron inmutables. Esta falta de comprensión sobre los cambios sociales fue contestada por el Estado con políticas nacionalistas que se caracterizaron por el incumplimiento administrativo de los preceptos constitucionales (GIANNINI, 1991, p. 76-77).

A principios del siglo XX, con la llegada del Estado de la pluralidad de clases en las sociedades industrializadas, la Administración Pública comienza a prestar diversos servicios públicos, como los ferrocarriles, los telégrafos, la educación, la sanidad pública, entre otros. Según Duguit, a medida que la Administración Pública se amplia e interviene en más servicios públicos, la ciudadanía exige mejoras en la prestación de estos servicios, debido, en parte, a los acelerados procesos de industrialización de las sociedades. Así, para Duguit (1913), la principal justificación para el ejercicio del poder estatal se encuentra en la prestación eficiente y continua de los servicios públicos, no en las nociones gaseosas de soberanía o de derechos naturales.

De esta forma, en la medida en que la Administración Pública cumpla con la prestación de los servicios públicos, cumple con su misión (DURÁN MARTÍNEZ, 2015, p. 39-62), sin que sea necesario mejorar la participación ciudadana en los asuntos públicos; pues se entiende que la Administración Pública tiene toda la competencia para intervenir y decidir "objetivamente" en razón a su experiencia y al manejo centralizado de los recursos que tiene por el momento. Al respecto, el Profesor Jaime Rodríguez-Arana (2013, p. 23-56) manifiesta:

Sencillamente, la Administración fue tomada, durante el apogeo del Estado de bienestar que denomino estático, por grupos políticos y a ella han servido casi en exclusiva. En lugar de explicar y justificar sus decisiones, se encerró en una torre de marfil, y decidió cerrarse a la sociedad consciente de que los partidos controlaban el resto de los poderes para acampar, mas o menos, en la impunidad. En este contexto, la Administración pública creció y creció a su amparo surgieron todo tipo de estructuras públicas, las más de las veces sometidas al derecho privado, para dar cobijo a la legión de personal de procedencia política que había que colocar para retribuir servicios prestados. Las manifestaciones de la mala Administración pública 
En el siglo XX, la legislación administrativa debe ser revisada conforme los parámetros constitucionales buscando la efectividad de los derechos. Al respecto, Giannini (1991, p. 76-77) considera que la legislación administrativa debió revisarse en por lo menos tres sentidos. El primero y más obvio, las Administraciones debieron ejecutar los preceptos constitucionales que habían sido inaplicados de modo fraudulento o simplemente inaplicados; el segundo, se debió desarrollar una legislación de justicia social; y el tercero, el Estado debió intervenir en los sectores en donde el poder político económico de las clases privilegiadas podían llegar a abusar de su posición dominante frente a la sociedad. En concreto, los preceptos constitucionales que debieron comenzarse a aplicar de forma más efectiva en el Derecho Administrativo fueron los derechos fundamentales, pues evidentemente el régimen exorbitante de la Administración permitió en muchas oportunidades la transgresión de los derechos de los administrados.

En cada Estado las reformas sobre la Administración Pública fueron numerosas, pero la pesada tradición autoritaria que acompaña el poder en los Estados ha dificultado en gran medida la efectividad de las reformas. En consecuencia, el enfásis colocado sobre el derecho-garantía a la buena Administración busca aportar en la construcción de un marco teórico sólido que ayude al cambio cultural que es requerido dentro de los Estados, para garantizar la efectividad de los derechos fundamentales en todos los niveles de gobierno.

En este contexto, la Carta de Derechos Fundamentales de la Unión Europea, aprobada en Niza en el año 2000, innovó al convertir el principio- hasta entonces tratado solamente bajo una perspectiva objetivaen derecho fundamental, otorgándole también una dimensión subjetiva susceptible de ser exigida (FUENTAJA PASTOR, 2008, p. 137). Es en este punto donde los autores evidencian su pionerismo, identificándolo como el primer documento jurídico a alzar la buena administración al status de genuino derecho fundamental del ciudadano (SÖDERMAN, 2001, p. 11; FERNÁNDEZ TOMÁS, 2001, p. 103).

La proclamación de la Carta fue fruto de la necesidad que se observó de acompañar, en el ámbito del Derecho Comunitario, la fuerte tendencia de los Estados-miembros de asegurar la tutela de los derechos del ser humano en sus Constituciones internas y en tratados 
internacionales. ${ }^{6}$ Esto porque, el respeto a los derechos y las libertades fundamentales consiste en uno de los cimientos sobre el cual se apoya la entidad supranacional (RODRÍGUEZ BEREIJO, 2001, p. 11). En América Latina, la Carta Iberoamericana de Derechos y Deberes del Ciudadano en relación con la Administración Pública también determina en el Capítulo Primero "el reconocimiento del derecho fundamental de la persona a la buena Administración Pública y de sus derechos y deberes componentes" (CLAD, 2013).

Aunque la Carta no es vinculante para los Estados signatarios, es importante porque otorga valiosos elementos para interpretar este nuevo derecho. Para compreender mejor en qué consiste el derecho fundamental a la buena Administración Pública, en el siguiente aparte se analizará el contenido jurídico y alcance de este concepto en el siglo XXI. ${ }^{7}$

\section{CONTENIDO JURÍDICO Y ALCANCE DEL DERECHO A LA BUENA ADMINISTRACIÓN PÚBLICA EN EL SIGLO XXI}

Para el Profesor Jaime Rodríguez-Arana (2013, p. 23-56), la buena administración es un derecho fundamental que "trae consigo un replanteamiento del derecho administrativo", puesto que la centralidad del ciudadano y su participación activa en la conformación de los intereses generales que persigue el Estado sugiere nuevos modelos de gestión de lo público que impactan de forma importante el Derecho Administrativo. Esto porque en la actualidad "los ciudadanos tienen el derecho de exigir determinados patrones o estándares en el funcionamiento de la administración" (RODRÍGUEZ-ARANA MUÑOZ, 2013, p. 23-56).

En Europa, la Carta de Derechos Fundamentales de la Unión Europea de diciembre de 2000 estableció de forma explicita en el artículo 41 el derecho a la buena administración (UNIÓN EUROPEA, 2000), y en consecuencia en la actualidad existe abundante doctrina y jurisprudencia ${ }^{8}$ sobre cómo este principio fundamenta el Derecho Comunitario en diversos ámbitos de la Administración Pública.

6 El Tratado de Lisboa firmado el 13 de diciembre de 2007, cuya vigencia inició en diciembre de 2009, incorporó por medio de su art. $6^{\circ}, 1$, la Carta de Derechos Fundamentales de Niza al conjunto normativo que rige la Unión Europea, confiriendo explícitamente el mismo valor jurídico de los tratados estructurantes del ente comunitario.

7 Para una perspectiva más general de los cambios en la Administración Pública y en el Derecho Administrativo en el siglo XXI, véase: BITENCOURT NETO, 2017, p. 207-225; BACHILO; SHMAKOV, 2017, p. 11-21 y CORREIA, 2016, p. 45-66.

8 Sobre la jurisprudencia respecto del tema, véase: CUCULOSKA, 2018. 
En concreto, el citado artículo estipula que: "Toda persona tiene derecho a que las instituciones y organos de la Unión traten sus asuntos imparcial y equitativamente y dentro de un plazo razonable". Conforme el numeral segundo, este derecho incluye en "particular": (i) el derecho de toda persona a ser oída antes de que se tome en contra suya una medida individual que le afecte desfavorablemente, (ii) el derecho de toda persona a acceder al expediente que le afecte, dentro del respeto de los intereses legitimos de la confidencialidad y del secreto profesional y comercial, (iii) la obligación que incumbe a la administración de motivar sus decisiones. Adicionalmente, el numeral tercero determina el derecho de reparación que tiene toda persona por los daños causados por las instituciones de la Comunidad, y el numeral cuarto señala que toda persona podrá dirigirse a las instituciones de la Unión en una de las lenguas de los Tratados y deberá recibir una contestación en esa misma lengua. En concepto de Natalia Aprile (2017), el artículo 41 de la Carta es "una disposición paraguas que comprende varios subderechos $\mathrm{y}$, como ha quedado esclarecido en la jurisprudencia del Tribunal de Justicia europeo, su enumeración no es taxativa pues al utilizar la expresión 'en particular' el legislador europeo dejó la puerta abierta a otros derechos no enumerados".

En este sentido, el derecho a la buena administración comprende un conjunto de derechos que tienen los ciudadanos en Estados de Derecho Democraticos, los cuales buscan garantizar el adecuado uso del poder por parte de la Administración Pública y los debidos controles por parte de la ciudadanía. ${ }^{9}$ Así lo reconoce el Profesor Jaime Rodríguez-Arana (2013, p. 23-56) cuando afirma:

Una buena Administración Pública es aquella que cumple con las funciones que le son propias en democracia. Es decir, una Administeación pública que sirve objetivamente a la ciudadanía, que realiza su trabajo con racionalidad, justificando sus actuaciones y que se orienta continuamente al interes general. Un interes general que en el Estado social y democratico de Derecho reside en la mejora permanente e integral de las condiciones de vida de las personas.

De esta forma, el derecho a la buena Administración busca consolidar una nueva forma de gobernar, en donde la participación de la ciudadanía es fundamental para motivar la razón de ser de la actividad de la 9 Una de las modalidades de control es justamente el control social, ejercido por los ciudadanos. En este sentido, véase: BITENCOURT; BEBER, 2015, p. 232-253; BITENCOURT; PAESE, 2015, p. 293-311. 
Administración Pública. Esto porque, en la actualidad, gobernar no puede ser un proceso unidireccional de los gobernantes a los gobernados, como en épocas pasadas, sino que debe ser un proceso bidireccional, en donde las interacciones amplias y sistémicas entre gobernantes y gobernados nutren continuamente las deciones públicas dentro de las comunidades (KOOIMAN, 2005).

En este contexto, los gobiernos de Iberoamerica adoptaron la "Carta Iberoamericana de los Derechos y Deberes del Ciudadano en relación con la Administración Pública" en la XXIII Cumbre Iberoamericana de Jefes de Estado y de Gobierno, celebrada en Ciudad de Panamá el 18 y 19 de octubre de 2013 (CLAD, 2013). La redacción de la Carta fue confiada por el Consejo Directivo de la entidad al Profesor Jaime Rodríguez-Arana Muñoz. ${ }^{10}$ En el preámbulo de la Carta, la buena Administración Pública se define como "una obligación inherente a los Poderes Públicos en cuya virtud el quehacer público debe promover los derechos fundamentales de las personas fomentando la dignidad humana de forma que las actuaciones administrativas armonicen criterios de objetividad, imparcialidad, justicia, equidad, y sean prestadas en plazo razonable".

La Carta enfatiza la centralidad del ser humano como principio y fin del Estado, determinando tambien que la buena Administración Pública tiene una triple funcionalidad: (i) es un principio de general aplicación del Derecho Administrativo; (ii) es una obligación de toda Administración en especial, al momento de promocionar condiciones de libertad e igualdad entre las personas y los grupos de forma real y efectiva; y (iii) desde la perpectiva de la persona, tambien es un auténtico y genuino derecho fundamental, del cual se derivan derechos concretos a favor de los ciudadanos, con el fin garantizar la protección a la dignidad humana en la práctica. ${ }^{11}$

En este sentido, el derecho a la buena Administración es un marco teórico que permite dirigirse a los problemas organizacionales (logisticos, culturales, económicos, etc.) que se presentan en todas las Administraciones Públicas, en razón a las dificultades operativas que pueden tener los equipos de trabajo al momento de garantizar el pleno goce de los derechos fundamentales, o al momento de permitir mayor participación con la ciudadania, o garantizar una debida prestación de cuentas; estableciendo

10 LAADMINISTRACIÓN AL DÍA. El catedrático Rodríguez-Arana redactará la Carta de Derechos Ciudadanos de Iberoamérica. 14.02.2013. Madrid, Instituto Nacional de Administración Pública. Disponible en: < http://laadministracionaldia.inap.es/noticia.asp?id=1500246>.

11 Sobre dicho principio, véase: MEZZAROBA; SILVEIRA, 2018, p. 273-293. 
como norte de la Administración Pública la centralidad del ser humano como principio y fin del Estado.

La Carta Iberoamericana es importante porque otorga una explicación sobre el significado de este derecho, estableciendo en el numeral 25 del Capítulo Tercero que: "Los ciudadanos son titulares del derecho fundamental a la buena Administración Pública, que consiste en que los asuntos de naturaleza pública sean tratados con equidad, justicia, objetividad, imparcialidad, siendo resueltos en plazos razonables al servicio de la dignidad humana". El mismo dispositivo establece que su contenido, en concreto, "se compone, entre otros, de los derechos señalados en los artículos siguientes, que se podrán ejercer de acuerdo con lo previsto por la legislación de cada país". El documento logró desintegrar la composición jurídica de este derecho general en los numerales subsecuentes del mismo capítulo.

En obra monográfica sobre el tema, anterior a la elaboración de la Carta, el Profesor Jaime Rodríguez-Arana - redactor del proyecto - ya arrojaba veinticuatro principios jurídicos que reputaba como centrales del derecho fundamental a la buena Administración Pública, cuya obediencia sería necesaria para que este último se considerara respetado. ${ }^{12}$ Determina, además, treinta y un derechos específicos que provienen de este derechosíntesis, sin perjuicio de otros, demostrando con esto la amplitud de la protección por él conferida al ciudadano en su trato con los Poderes Públicos. ${ }^{13}$ La mayoría de los principios y derechos derivados del derecho

$12 \mathrm{El}$ autor alude a los siguientes principios, explicando en seguida el contenido de cada uno de ellos: 1. Principio de juridicidad; 2. Principio de servicio objetivo a los ciudadanos; 3. Principio promocional; 4. Principio de racionalidad; 5. Principio de igualdad de trato; 6. Principio de eficacia; 7. Principio de publicidad de las normas, de los procedimientos y del entero quehacer administrativo en el marco del respeto del derecho a la intimidad y de las reservas que por razones acreditadas de confidencialidad o interés general sea pertinente en cada caso, en los procedimientos para el dictado de actos administrativos; 8 . Principio de seguridad jurídica, de previsibilidad y certeza normativa; 9. Principio de proporcionalidad; 10. Principio de ejercicio normativo del poder; 11. Principio de imparcialidad e independencia; 12. Principio de relevancia; 13. Principio de coherencia; 14. Principio de buena fe; 15. Principio de confianza legítima; 16. Principio de asesoramiento; 17. Principio de responsabilidad; 18. Principio de facilitación; 19. Principio de celeridad; 20. Principio de transparencia y acceso a la información de interés general; 21. Principio de protección de la intimidad; 22. Principio de ética; 23. Principio de debido proceso; 24. Principio de cooperación. RODRÍGUEZ-ARANA MUÑOZ, 2012a, p. 169-172.

13 El derecho general fundamental de los ciudadanos a una buena Administración pública finalmente, se puede concretar, entre otros, en los siguientes derechos subjetivos de orden administrativo: 1. derecho a la motivación de las actuaciones administrativas; 2. derecho a la tutela administrativa efectiva; 3 . derecho a una resolución administrativa en plazo razonable; 4. derecho a una resolución justa de las actuaciones administrativas; 5 . derecho a presentar por escrito o de palabra peticiones de acuerdo con lo que se establezca en las normas, en los registros físicos o informáticos; 6 . derecho a respuesta oportuna y eficaz de las autoridades administrativas; 7. derecho a no presentar documentos que ya obren en poder de la Administración pública; 8 . derecho a ser oído siempre antes de que se adopten medidas que les puedan afectar desfavorablemente; 9. derecho de participación en las actuaciones administrativas 
fundamental a la buena Administración Pública propuestos en su libro fueron incorporados a la Carta Iberoamericana, respectivamente, en sus Capítulos Segundo (numerales 2 al 24) y Tercero (26 al 46). Como se ve, el documento aporta grandes avances en lo que concierne al derecho en debate, progresando más allá de la tímida relación de derechos inicialmente propuesta por la Carta de Derechos Fundamentales de la Unión Europea (HACHEM, 2014).

El reconocimiento del derecho a la buena Administración se justifica a causa de tres razones principales. La primera, de naturaleza simbólica, porque enfatiza el carácter del servicio del Poder Público para con la persona humana, con la intención de garantizar la plena y eficaz realización de los derechos fundamentales y del interés general. ${ }^{14} \mathrm{La}$ segunda razón, de naturaleza jurídica, porque eleva los postulados de la buena Administración Pública al nivel de derecho fundamental, aún que en algunos países dichos postulados no estén protegidos expresamente en las Constituciones (como, por ejemplo, los deberes de buena fe y eficacia administrativa). La tercera razón, también de carácter jurídico, porque determina la posibilidad de hacer exigible el cumplimiento de los principios

en que tengan interés, especialmente a través de audiencias y de informaciones públicas; 10. derecho a una indemnización justa en los casos de lesiones de bienes o derechos como consecuencia del funcionamiento de los servicios de responsabilidad pública; 11. derecho a servicios públicos y de interés de general de calidad; 12. derecho a elegir los servicios de interés general de su preferencia; 13. derecho a opinar sobre el funcionamiento de los servicios de responsabilidad administrativa; 14. derecho a conocer las obligaciones y compromisos de los servicios de responsabilidad administrativa; 15. derecho a formular alegaciones en cualquier momento del procedimiento administrativo; 16. derecho a presentar quejas, reclamaciones y recursos ante la Administración; 17. derecho a interponer recursos ante la autoridad judicial sin necesidad de agotar la vía administrativa previa, de acuerdo con lo establecido en las leyes; 18 . derecho a conocer las evaluaciones de los entes públicos y a proponer medidas para su mejora permanente; 19. derecho de acceso a los expedientes administrativos que les afecten en el marco del respeto al derecho a la intimidad y a las declaraciones motivadas de reserva que en todo caso habrán de concretar el interés general al caso concreto; 20. derecho a una ordenación racional y eficaz de los archivos públicos; 21. derecho de acceso a la información de interés general; 22. derecho a copia sellada de los documentos que presenten a la Administración pública; 23. derecho a ser informado y asesorado en asuntos de interés general; 24. derecho a ser tratado con cortesía y cordialidad; 25 . derecho a conocer el responsable de la tramitación del procedimiento administrativo; 26. derecho a conocer el estado de los procedimientos administrativos que les afecten; 27 . derecho a ser notificado por escrito o a través de las nuevas tecnologías de las resoluciones que les afecten en el más breve plazo de tiempo posible, que no excederá de los cinco días; 28. derecho a participar en asociaciones o instituciones de usuarios de servicios públicos o de interés general; 29. derecho a actuar en los procedimientos administrativos a través de representante; 30 . derecho a exigir el cumplimiento de las responsabilidades del personal al servicio de la Administración pública y de los particulares que cumplan funciones administrativas; 31 . derecho a recibir atención especial y preferente si se trata de personas en situación de discapacidad, niños, niñas, adolescentes, mujeres gestantes o adultos mayores, y en general de personas en estado de indefensión o de debilidad manifiesta". RODRÍGUEZ-ARANA MUÑNZ, 2012a, p. 172-174.

14 En este sentido, véase la defensa de un Derecho Administrativo social por autores como: GABARDO, 2017; BALBÍN, 2014; RODRÍGUEZ-ARANA MUÑOZ, 2015a; RODRÍGUEZ-ARANA MUÑOZ, 2015b; DELPIAZZO, 2014. 
constitucionales que rigen la función administrativa (HACHEM, 2014).

Teniendo en cuenta las anteriores consideraciones, a continuación se presentarán las principales características que derivan de la buena Administración Pública según el Profesor Jaime Rodríguez-Arana.

\section{PRINCIPALES CARACTERÍSTICAS DE LA BUENA ADMINISTRACIÓN PÚBLICA}

Tomando como base la investigación del Profesor Jaime Rodríguez-Arana (2013, p. 23-56) sobre "La buena Administración como principio y como derecho fundamental en Europa", esta sección será dedicada a resaltar las seis principales características que fueron identificadas por el destacado autor.

La primera trata sobre la centralidad que debe tener la persona dentro de un Estado de Derecho democrático, donde los ciudadanos deben convertirse en sujetos activos, y con ello, "protagonistas en la determinación del interés general y, en la evaluación de las políticas públicas". ${ }^{15}$ La segunda característica enfatiza la importancia de una Administración Pública abierta a estudiar las condiciones objetivas que presenta cada situación, de forma tal que conoce bien las circunstancias sociales, económicas, culturales y políticas que afectan cada comunidad en particular, con la finalidad de buscar estrategias que moderen y equilibren los diversos intereses. A esta característica el Profesor Rodríguez-Arana llama "apertura a la realidad", dejando claro que las perspectivas ideológicas que parten de "prejuicios ideológicos diseñados para su proyección mecánica y unilateral sobre la realidad, no tienen sentido".

La tercera característica, denominada "Metodología del entendimiento", enfatiza la importancia del diálogo como mecanismo principal de consenso dentro de Estados democráticos donde existe pluralidad de intereses. De esta forma, Rodríguez-Arana (2013, p. 23-56) afirma que la buena Administración Pública "se hace entender, necesita afirmar, explicar, aclarar, razonar. Por una razón elemental: porque el dueño y señor de la Administración pública es el pueblo, y a él los dirigentes deben rendir cuentas permanentemente de las decisiones que adoptan".

La cuarta característica, sobre la promoción de la participación, afirma que una buena Administración necesita de la presencia y

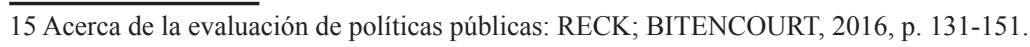


participación real de toda la ciudadanía, ${ }^{16}$ evitando exclusiones de sectores económicos, sociales o institucionales, pues la principal razón de ser de la Administración Pública es la atención de todos los intereses con moderación y equilibrio.

En este sentido, es necesario un cambio de actitud de muchos servidores públicos, pues la efectiva participación de "todos" los sectores exige mayores mecanismos de inclusión y de receptividad, esto es, capacidad de escucha y sensibilidad suficiente para captar las preocupaciones e intereses presentes en los diversos sectores y grupos. Por lo tanto, la tradicional suficiencia y prepotencia que caracterizaba inicialmente las tecnocracias en los Estados debe transformarse en mayor humildad y respeto por la diferencia, para lograr mayor conocimiento sobre las personas y los intereses presentes en las comunidades.

La quinta característica analiza la vinculación de la ética, dejando en claro qué si el centro de la Administración pública es la persona, la buena Administración debe trabajar en generar un ambiente "en el que cada ciudadano pueda ejercer su libertad de forma solidaria". Así, la configuración ética no puede entenderse como la articulación de una propuesta concreta y definida a priori, sino por el contrario las respuestas deben ser construidas de forma colaborativa y permanente entre todos los actores, teniendo en cuenta las anteriores características de participación y conocimiento de la realidad, de forma tal que es posible rectificar sobre la marcha, pues el buen administrador "ha de tener claro que no es infalible, que sus opiniones, sus valoraciones están siempre mediatizadas por la información de que parte, que es siempre limitada, necesariamente incompleta" (RODRÍGUEZ-ARANA MUÑOZ, 2013, p. 23-56).

La sexta característica estudia la innovación y la sociedad del conocimiento, afirmando la importancia de mejorar la calidad de la cultura cívica de las personas mediante procesos de formación, utilizando adecuadamente las nuevas tecnologías disponibles. Desde esta perspectiva, las nuevas tecnologías de la información y la comunicación -TICs- ayudan a mejorar las relaciones entre la Administración pública y la ciudadanía, no solo porque el conocimiento tiene la capacidad de mejorar la vida de las personas, sino también porque en la actualidad el ciudadano cuenta con más herramientas para acceder a la información pública. No obstante, Rodríguez-Arana deja claro que es importante trabajar en el mundo de la educación y la formación de los funcionarios públicos y de los ciudadanos

16 En este sentido: CARMONA GARIAS, 2016, p. 29-60; SCHIER; MELO, 2017, p. 127-147. 
para obtener los mejores resultados.

Finalmente, la sexta característica habla de la sensibilidad social que deriva del principio de la centralidad de la persona, y que se refleja en actitudes solidarias que permitan soluciones reales a cuestiones colectivas. Por lo tanto, las decisiones públicas deben estar orientadas a la cooperación, la convivencia, la integración y la confluencia de intereses, lo que implica obligatoriamente entender a los diferentes interlocutores para mejorar las condiciones de vida de los ciudadanos.

Teniendo en cuenta las anteriores características, es posible verificar como el derecho a la buena Administración establece como metodología principal conocer mejor a las personas y a las comunidades, lo que evidentemente implica un cambio de perspectiva fundamental sobre el Derecho Administrativo, que como ya fue subrayado en las secciones anteriores, se caracterizó históricamente por construir la teoría del poder de arriba hacia abajo, esto es, con base en relaciones de subordinación entre gobernantes y gobernados, entre quien tiene el poder de mandar y quien tiene el deber de obedecer (BOBBIO, 1989, p. 15).

De esta forma, el Profesor Rodríguez-Arana (2013, p. 2356) acierta cuando declara que la buena Administración es un derecho fundamental que "trae consigo un replanteamiento del derecho administrativo". Pero ¿cómo sucede la transformación hacia la buena Administración Pública? Para responder esta pregunta, en la siguiente sección se analizará la buena Administración Pública en Colombia, dado que en el concepto adoptado en este estudio, las reformas sucedidas sobre la Administración Pública en Colombia representan un esfuerzo continuo y permanente de varias Administraciones y de varios períodos de gobierno, que buscaron implementar una política pública coherente a las necesidades de la sociedad y del Estado en el siglo XXI.

\section{LA BUENA ADMINISTRACIÓN PÚBLICA EN COLOMBIA}

En Colombia, la Constitución no reconoce de forma explicita el derecho a la buena Administración Pública como sucede en la Carta de Niza en Europa, pero aún así se puede verificar que el ordenamiento jurídico colombiano ha desarrollado diversas instituciones que buscan ampliar la participación de la ciudadanía en los asuntos públicos, así como también buscan mejorar los niveles de eficacia, transparencia y rendición 
de cuentas de las entidades estatales. ${ }^{17}$ Al respecto, Natalia Aprile (2017) afirma que a pesar de que la Constitución colombiana no reconoce expresamente el derecho a una buena Administración, "sí existe un sistema jurídico concertado que proclama el empoderamiento del ciudadano y la exigencia de unas condiciones de actuación para la administración".

Para Rivero y Arenas (2018, p. 271-272), Colombia al ser un Estado Social y Democrático de Derecho debe transformar su modelo de actuación estatal conforme los postulados de la buena Administración, buscando garantizar la calidad, la participación de la ciudadanía y la prevalencia del interés general, como parte de garantías mínimas para el ejercicio del poder democrático. Sobre el marco jurídico de la buena Administración, los referidos autores afirman:

En Colombia, al igual que en el derecho español, a pesar de que no se incluyó una norma constitucional expresa que lo contenga, si existen varios principios vinculantes encaminados a que la administración sea buena; concretamente, se puede derivar su existencia de la lectura tanto del preámbulo como de los artículos 1, 2, 83 y 209 (de la Constitución). Así mismo, en lo concerniente al derecho administrativo colombiano, se puede desprender su existencia en diversas leyes; particularmente, en la Ley 489 de 1998 sobre la Organización de la Función Administrativa (artículos 3 y 4) o en la Ley 1437 de 2011 que establece el Código de Procedimiento Administrativo y de lo Contencioso administrativo (artículos 1, 3 y 103).

Aquí es importante resaltar que el Consejo de Estado, en Sentencia reciente de octubre de 2016 del Magistrado Ponente Jaime Orlando Santofimio Gamboa, señaló que la clausula de buena Administración es un principio y un derecho incorporado en el ordenamiento jurídico colombiano:

Existe una cláusula de competencia especial para la Administración que deriva de las funciones que le asignó el constituyente en el artículo 209 constitucional, siendo estas: i) Estar al servicio de los intereses generales, por oposición a los partidistas, gremiales u otros que no representen el bien común; ii) Ceñirse a los principios de igualdad, moralidad, eficacia, economía, celeridad, imparcialidad y publicidad; y, por

17 Una de las maneras de promover la transparencia es mediante la garantía del derecho de acceso a la información pública. En los últimos años dicho derecho ha ganado una protección cada vez más expresiva en los países de América Latina. Sobre el tema en Brasil, véase: MARTINS, 2014, p. 127146; PERLINGEIRO, 2014, p. 209-227; VALIM, 2016, p. 169-181; PERLINGEIRO; DÍAS; LIANI, 2016, p. 143-197. En Argentina: BUTELER, 2014, p. 61-106; BELLOCHIO, 2016, p. 39-51. En Uruguay: SCHIAVI, 2014, p. 13-45; SCHIAVI, 2015, p. 137-168. 
último, iii) Ejercer estas funciones mediante los instrumentos de la descentralización, la delegación y la desconcentración de ellas. (...) el principio jurídico de la Buena Administración (...) postulado normativo que ordena, en la mayor medida de las posibilidades fácticas y jurídicas, que la Administración garantice los derechos de los administrados cuando entran en interacción con ella, ejecute de buena fe y bajo el estándar de la debida diligencia los deberes funcionales que el ordenamiento jurídico convencional, constitucional y legal le ha confiado y adopte las decisiones que correspondan de manera razonable y ponderada conforme a los valores, principios y reglas que se desprenden del marco jurídico legal, constitucional y convencional.

En este orden de ideas, es posible afirmar que en Colombia existe un marco normativo robusto que permite exigir el derecho a una buena Administración Pública en todos los niveles de gobierno. Sin embargo, es importante analizar en concreto cómo se han interpretado los preceptos constitucionales y legales para que la Administración Pública sea considerada "buena".

Para comenzar, es interesante destacar que el documento Conpes 2790 de 1995, titulado "Gestión Pública orientada a resultados", ${ }_{18}$ determinó un marco conceptual importante para prestar mejores servicios a la ciudadanía, mejorando la comunicación y la participación. Este documento también enfatiza sobre la importancia de usar de forma eficiente y eficaz los recursos públicos. Posteriormente, el Conpes 3248 de 2003 determinó los lineamientos generales, el alcance y los mecanismos de evaluación del Programa de Renovación de la Administración Pública (PRAP), el cual tiene por objetivo promover la construcción de una Administración Pública centrada en los ciudadanos, en cuya concepción, ejecución y control participa activamente la comunidad.

En desarrollo de los anteriores lineamientos estratégicos, la Administración Pública colombiana comenzó un proceso de transformación importante que buscó pasar de un modelo legal-funcional a un modelo gerencial que se preocupa con los resultados, la participación ciudadana, la calidad de los servicios y bienes, la responsabilidad, la eficiencia y la innovación en los procesos públicos.

18 Conpes - Consejo Nacional de Política Económica y Social es la máxima autoridad nacional de planeación y se desempeña como organismo asesor del Gobierno en todos los aspectos relacionados con el desarrollo económico y social del país. Para lograrlo, coordina y orienta a los organismos encargados de la dirección económica y social en el Gobierno, a través del estudio y aprobación de documentos sobre el desarrollo de políticas generales que son presentados en sesión. El Departamento Nacional de Planeación desempeña las funciones de Secretaría Ejecutiva del Conpes y Conpes Social, y por lo tanto es la entidad encargada de coordinar y presentar todos los documentos para discutir en sesión. 
Así, el Estado colombiano, comprometido con las nuevas exigencias que impone el siglo XXI, buscó crear una nueva cultura de la calidad y del compromiso con el servicio público en las entidades estatales, para lo cual ordenó la implementación del Sistema de Gestión de la Calidad, mediante la aprobación de la Ley 872 de 2003. Cuando la Ley era discutida en el Congreso de la República, el ponente de la Ley, José Ovidio Claros Polanco, definió la calidad como "el cumplimiento de estándares que aseguren la satisfacción de las necesidades y expectativas del destinatario o usuario del servicio", ${ }^{19}$ y la gestión de la calidad fue definida como:

(...) la manera de mejorar constantemente el desempeño y rendimientos en los niveles funcionales de una organización, al utilizar todo el recurso humano y el capital disponible. Para estos logros, se requiere de una cultura organizacional en cada una de las entidades del Estado, así mismo debemos crear conciencia en nuestros funcionarios públicos, el sentimiento de transparencia, responsabilidad y compromiso por la entidad donde labora y el trabajo que desempeña. (...) la gestión de la calidad debe entenderse como un proceso controlable y no como un suceso aleatorio; debe realizarse por todos los miembros de una organización o entidad y definirse una estructura funcional de trabajo que los involucre con el propósito de asegurar la calidad. ${ }^{20}$

Teniendo en cuenta el mandato legal del Congreso de la República, el Gobierno Nacional tuvo 12 meses para expedir una Norma Técnica de Gestión de la Calidad en el Estado, contados desde la expedición de la Ley 872 de 2003. Para la expedición de esta Norma, el Gobierno Nacional realizó consulta pública en 213 entidades estales, quienes de marzo a julio de 2004 analizaron la propuesta inicial de Norma Técnica, para efectos de realizar comentarios y proponer ajustes y mejoras. Luego de 11 reuniones del Comité Técnico para la elaboración de la Norma, esta fue aprobada mediante la expedición del Decreto 4110 de 2004, que adopta oficialmente la Norma Técnica de Calidad para el Estado NTCGP 1000:2004 (VALENCIA-TELLO, 2005). Al respecto, el Director del Departamento Administrativo de la Función Pública, Dr. Fernando Grillo Rubiano (2004), afirmó lo siguiente:

19 CONGRESO DE LA REPÚBLICA (2003). Ponencia para Primer Debate al Proyecto de Ley 107 de 2002 Senado, 286 de 2003 Cámara. Gaceta 444 del 28 de agosto de 2003. Disponible en: <http:// www.secretariasenado.gov.co/index.php/gaceta-del-congreso $>$.

20 Ibidem.

Veredas do Direito, Belo Horizonte, $\cdot$ v.15 $\cdot$ n.33 $\cdot$ p.101-130 $\cdot$ Setembro/Dezembro de 2018 
La calidad no es el resultado de la casualidad sino de la voluntad y la planificación del sistema. Planificar el sistema no impone otro reto que definir la política explicita para la calidad, reconocer a cliente como el factor clave que define los lineamientos de la calidad; identificar los sistemas de la organización para evitar duplicidades, gestionar el talento humano como eje de cambio y generación de condiciones laborales que promuevan la creatividad y la innovación.

En este sentido, se puede afirmar que en Colombia el principal marco jurídico que promueve la buena Administración Pública conforme los parámetros del siglo XXI se encuentran enunciados en la Ley 872 de 2003, por medio de la cual se crea el Sistema de Gestión de la Calidad para el sector público, determinando los requisitos mínimos que deben cumplir las entidades públicas para garantizar la satisfacción de los ciudadanos.

En la actualidad, todas las entidades públicas del nivel nacional cuentan con un Sistema de Gestión de la Calidad, el cual es auditado regularmente por equipos internos y órganos de control externos, especialmente, por la Contraloría General de la República. Aunque son muchos los avances realizados en materia de Gestión de la Calidad en el Estado Colombiano, es evidente que la cultura organizacional no cambia con la expedición de una norma y, en consecuencia, a lo largo de estos años se han realizado varios ajustes a la Norma Técnica ${ }^{21}$ y se han desarrollado diferentes Guías Metodológicas para explicar de forma más explícita los nuevos requisitos técnicos que deben cumplir las entidades y los funcionarios públicos en el ejercicio de sus funciones. De esta forma, los Sistemas de Gestión de la Calidad deben revisarse constantemente para asegurar que los bienes y servicios ofrecidos a los ciudadanos cuenten con los estándares previamente identificados como requisitos de calidad, cuidando siempre el cumplimiento de otros requisitos importantes dentro del sector público, tales como la transparencia, participación, rendición de cuentas y eficiencia en las entidades públicas.

\section{CONSIDERACIONES FINALES}

Al inicio del artículo fue posible observar que en los primeros años del Derecho Administrativo, esta rama jurídica convivió con prácticas 21 El Decreto 4485 de 2009 actualizó la Norma Técnica de Calidad -NTCGP 1000:2009-conforme consulta pública realizada a varias entidades. Asimismo, el nuevo Modelo Integrado de Planeación y Gestión -MIPG- adoptado mediante el Decreto 1499 de 2017, articula el nuevo Sistema de Gestión, que integra los anteriores sistemas de Gestión de la Calidad y de Desarrollo Administrativo, con el Sistema de Control Interno. 
autoritarias, en razón a la necesidad de orden y seguridad jurídica que caracterizó el Estado moderno. La racionalización del poder bajo el modelo jerárquico y centralizado de las estructuras administrativas otorgó poderes unidireccionales a las autoridades públicas, impidiendo la participación de la ciudadanía y la rendición de cuentas sobre los procesos públicos.

Por ello, el derecho a la buena Administración -como bien lo explica el Profesor Jaime Rodríguez-Arana- representa un replanteamiento del Derecho Administrativo, pues la centralidad del ciudadano y la posibilidad de participación activa dentro los procesos públicos obliga a consolidar nuevos modelos de gestión pública que permitan mayor comunicación con la ciudadanía y los diversos grupos de interés.

En este sentido, el esfuerzo realizado por el gobierno colombiano para consolidar un nuevo Sistema de Gestión de la Calidad en el sector público, centralizado en satisfacer las demandas de los ciudadanos, representa un nuevo modelo de gerencia que busca cumplir con los postulados constitucionales y legales, y con ello, materializar una Administración Pública más eficaz, transparente y comprometida con la rendición de cuentas sobre las decisiones adoptadas. Aún así, es evidente que los cambios normativos requieren de mucha pedagogía para que sean realmente incorporados por funcionarios públicos y ciudadanos en el día a día.

En este orden de ideas, es necesario continuar investigando sobre la efectividad real de estos cambios normativos en las estructuras administrativas y en la cultura organizacional de las entidades. Asimismo, se requiere mayor conocimiento sobre las metodologías utilizadas hasta el momento para conocer mejor a las personas y a las comunidades a quienes se dirigen los bienes y servicios, evaluando la capacidad de las entidades públicas para permitir mayor participación y rendición de cuentas en los procesos públicos.

\section{REFERENCIAS}

APRILE, Natalia. El derecho a una buena administración: un derecho fecundo en Latinoamérica. In: RESTREPO, Manuel (Ed.). Derecho administrativo: reflexiones contemporáneas. Bogotá: Universidad del Rosario, 2017.

ASIMOW, Michael. Cinco modelos de adjudicação administrativa (Justiça Administrativa). Revista de Investigações Constitucionais, Curitiba, vol. 
4, n. 1, p. 129-165, jan./abr. 2017. DOI: 10.5380/rinc.v4i1.50154.

BACHILO, Illaria; SHMAKOV, Maksim. The transformation of State and Law institutions in the information society. $A \& C-$ Revista de Direito Administrativo \& Constitucional, Belo Horizonte, ano 17, n. 69, p. 11-21, jul./set. 2017. DOI: 10.21056/aec.v17i69.820.

BALBÍN, Carlos F. Un Derecho Administrativo para la inclusión social. A\&C-Revista de Direito Administrativo \& Constitucional, Belo Horizonte, ano 14, n. 58, p. 33-59, out./dez. 2014.

BELLOCHIO, Lucía. Access to public information in Argentina with particular reference to personal and institutional data protection. $A \& C-$ Revista de Direito Administrativo \& Constitucional, Belo Horizonte, ano 16, n. 65, p. 39-51, jul./set. 2016.

BITENCOURTNETO, Eurico. Transformações doEstado eaAdministração Pública no século XXI. Revista de Investigações Constitucionais, Curitiba, vol. 4, n. 1, p. 207-225, jan./abr. 2017. DOI: 10.5380/rinc.v4i1.49773.

BITENCOURT, Caroline Müller; BEBER, Augusto Carlos de Menezes. O controle social a partir do modelo da gestão pública compartida: da insuficiência da representação parlamentar à atuação dos conselhos populares como espaços públicos de interação comunicativa. Revista de Direito Econômico e Socioambiental, Curitiba, v. 6, n. 2, p. 232-253, jul./ dez. 2015. doi: 10.7213/rev.dir.econ.socioambienta.06.002.AO09.

BITENCOURT, Caroline Müller; PASE, Eduarda Simonetti. A necessária relação entre democracia e controle social: discutindo os possíveis reflexos de uma democracia "não amadurecida" na efetivação do controle social da administração pública. Revista de Investigações Constitucionais, Curitiba, vol. 2, n. 1, p. 293-311, jan./abr. 2015. DOI: 10.5380/rinc.v2i1.436.

BOBBIO, Norberto. Estado, gobierno y sociedad: por una teoría general de la política. Traducción: José F. Fernández Santillán. México: Editora FCE, 1989.

BOBBIO, Norberto; MATTEUCCI, Nicola; PASQUINO, Gianfranco. Dicionário de Política. 13. ed. Traducción Carmen C, Varriale et al. Coord. Trad. João Ferreira. Rev. geral. João Ferreira e Luis Guerreiro Pinto Cacais. Brasília: Editora Universidade de Brasília, 2010. 
BUTELER, Alfonso. La transparencia como política pública contra la corrupción: aportes sobre la regulación de derecho de acceso a la información pública. $A \& C-$ Revista de Direito Administrativo \& Constitucional, Curitiba, v. 14, n. 58, p. 61-106, out./dez., 2014.

CANE, Peter. Por que ter tribunais administrativos?. A\&C-Revista de Direito Administrativo \& Constitucional, Belo Horizonte, ano 17, n. 69, p. 77-110, jul./set. 2017. DOI: 10.21056/aec.v17i69.484.

CARMONA GARIAS, Silvia. Nuevas tendencias en la participación ciudadana en España: ¿socializando la gestión pública o socializando la responsabilidad política? A\&C - Revista de Direito Administrativo \& Constitucional, Belo Horizonte, ano 16, n. 66, p. 29-60, out./dez. 2016. DOI: $10.21056 /$ aec.v16i66.362.

CARRILLO DONAIRE, Juan Antonio. Buena administración, ¿Un principio, un mandato o un derecho subjetivo? In: Los principios jurídicos del derecho administrativo. Madrid: La Ley, 2010.

\section{CLAD - CENTRO LATINOAMERICANO DE ADMINISTRACIÓN} PARA EL DESARROLLO. Carta Iberoamericana de los Derechos y Deberes del Ciudadano en Relación con la Administración Pública. Caracas, 2013. Disponible en: <http://www.clad.org/documentos/ declaraciones/Carta\%20Iberoamericana $\% 20 \mathrm{de} \% 201$ os $\% 20$ deberes $\% 20$ y\%20derechos\%20-\%20documento\%20aprobado.pdf/view>.

CONGRESO DE LA REPÚBLICA. Ponencia para Primer Debate al Proyecto de Ley 107 de 2002 Senado, 286 de 2003 Cámara. Gaceta 444 del 28 de agosto de 2003. Disponible en: $<$ http://www.secretariasenado. gov.co/index.php/gaceta-del-congreso $>$.

CORREIA, José Manuel Sérvulo. Os grandes traços do direito administrativo no século XXI. A\&C-Revista de Direito Administrativo \& Constitucional, Belo Horizonte, ano 16, n. 63, p. 45-66, jan./mar. 2016.

CORVALÁN, Juan G. Los ejes centrales de la división de poderes en el Estado Constitucional de Derecho. Revista de Investigações Constitucionais, Curitiba, vol. 2, n. 1, p. 225-256, jan./abr. 2015. DOI: 10.5380/rinc.v2i1.43661

COSTA, Pietro. Estado de Direito e direitos do sujeito: o problema 
dessa relação na Europa Moderna. In: FONSECA, Ricardo Marcelo; SEELAENDER, Airton Cerqueira Leite. História do Direito em Perspectiva: do Antigo Regime à Modernidade. Curitiba: Editora Juruá, 2008.

CUCULOSKA, Irena The Scope of Application of the Charter's Right to Good Administration of the European Union. Journal of Liberty and International Affairs, Bitola, v. 3, n. 3, p. 20-28, 2018.

DELPIAZZO, Carlos E. Centralidad del administrado en el actual Derecho Administrativo: impactos del Estado Constitucional de Derecho. Revista de Investigações Constitucionais, Curitiba, vol. 1, n. 3, p. 7-32, set./dez. 2014. DOI: 10.5380/rinc.v1i3.40514.

DUGUIT, Léon. Les transformations du droit public. Paris: Librairie Armand Colin, 1913.

DURÁN MARTíNEZ, Augusto. Estado Constitucional de Derecho y servicios públicos. A\&C - Revista de Direito Administrativo \& Constitucional, Belo Horizonte, ano 15, n. 60, p. 39-62, abr./jun. 2015.

FERNÁNDEZ TOMÁS, Antonio. La Carta de Derechos Fundamentales de la Unión Europea. Valencia: Tirant lo Blanch, 2001.

FIORAVANTI, Maurizio. Los derechos fundamentales: apuntes de historia de las constituciones. 5. ed. Madrid: Trotta, 2007.

FUENTETAJA PASTOR, Jesús Angel. "El derecho a la buena administración en la Carta de los derechos fundamentales de la Unión Europea". Revista de Derecho de la Unión Europea, Madrid, n. 15, pp. 137-153, jun/dez. 2008.

GABARDO, Emerson. O princípio da supremacia do interesse público sobre o interesse privado como fundamento do Direito Administrativo Social. Revista de Investigações Constitucionais, Curitiba, v. 4, n. 2, p. 95-130, maio/ago. 2017.

GABARDO, Emerson; HACHEM, Daniel Wunder. O suposto caráter autoritário da supremacia do interesse público e das origens do direito administrativo: uma crítica da crítica. In: BACELLAR FILHO, Romeu Felipe; HACHEM, Daniel Wunder (Coord.). Direito administrativo e interesse público: estudos em homenagem ao Professor Celso Antônio 
Bandeira de Mello. Belo Horizonte: Fórum, 2010.

GIANNINI, Massimo Severo. Derecho Administrativo. Trad. Luis Ortega. Volumen Primero. Madrid: Ministerio para las Administraciones Públicas, 1991.

GRILLO RUBIANO, Fernando. "Introducción”. In: Gestión de la Calidad en el Sector Público. Norma Técnica de Calidad en la Gestión Pública (NTCGP 1000:2004). Bogotá, 2004.

HACHEM, Daniel Wunder. Tutela administrativa efetiva dos direitos fundamentais sociais: por uma implementação espontânea, integral e igualitária. Curitiba, 2014. 614 f. Tesis (Doctorado en Derecho) - Programa de Posgrado en Derecho, Universidade Federal do Paraná.

KOOIMAN, J. Gobernar en gobernanza. In: CERRILLO I MARTÍNEZ, A. La gobernanza hoy: 10 textos de referencia. Madrid: INAP, 2005.

KRISTJÁNSDÓTTIR, Margrét V. Good Administration as a Fundamental Right. Icelandic Review on Politics \& Administration, Reykjavík, v. 9, n. 1, p. 237-255, 2013.

LA ADMINISTRACIÓN AL DÍA. El catedrático Rodríguez-Arana redactará la Carta de Derechos Ciudadanos de Iberoamérica. 14.02.2013. Madrid, Instituto Nacional de Administración Pública. Disponible en: $<\mathrm{http}$ //laadministracionaldia.inap.es/noticia.asp?id=1500246>.

MARTINS, Ricardo Marcondes. Direito fundamental de acesso à informação. A\&C-Revista de Direito Administrativo \& Constitucional, Belo Horizonte, ano 14, n. 56, p. 127-146, abr./jun. 2014.

MEZZAROBA, Orides; SILVEIRA, Vladmir Oliveira da. The principle of the dignity of human person: A reading of the effectiveness of citizenship and human rights through the challenges put forward by globalization. Revista de Investigações Constitucionais, Curitiba, vol. 5, n. 1, p. 273-293, jan./abr. 2018. DOI: 10.5380/rinc.v5i1.54099.

PERLINGEIRO, Ricardo. A codificação do direito à informação na América Latina. A\&C - Revista de Direito Administrativo \& Constitucional, Belo Horizonte, ano 14, n. 56, p. 209-227, abr.jun. 2014.

PERLINGEIRO, Ricardo. Desafios contemporâneos da justiça 
administrativa na América Latina. Revista de Investigações Constitucionais, Curitiba, vol. 4, n. 1, p. 167-205, jan./abr. 2017. DOI: 10.5380/rinc. v4i1.50155.

PERLINGEIRO, Ricardo; DÍAZ, Ivonne; LIANI, Milena. Princípios sobre o direito de acesso à informação oficial na América Latina. Revista de Investigações Constitucionais, Curitiba, vol. 3, n. 2, p. 143-197, maio/ ago. 2016.

RAMÍREZ BROUCHOUD, María Fernanda. Gobernanza y legitimidad democrática. Reflexión Política, Medellín, n. 12, pp. 96-107, 2010.

RECK, Janriê Rodrigues; BITENCOURT. Caroline Müller. Categorias de análise de políticas públicas e gestão complexa e sistêmica de políticas públicas. A\&C-Revista de Direito Administrativo \& Constitucional, Belo Horizonte, ano 16, n. 66, p. 131-151, out./dez. 2016. DOI: 10.21056/aec. v16i66.364.

RIVERO ORTEGA, Ricardo; ARENAS MENDOZA, Hugo Andrés. Derecho Administrativo General. Bogotá: Editora Ibañez, 2018.

RODRÍGUEZ BEREIJO, Álvaro. La Carta de los derechos fundamentales de la Unión Europea y la protección de los derechos humanos. In: FERNÁNDEZ SOLA, Natividad (Coord.). Unión Europea y derechos fundamentales en perspectiva constitucional. Madrid: Dykinson, 2001.

RODRÍGUEZ-ARANA MUÑOZ, Jaime. Dimensiones del Estado Social y derechos fundamentales sociales. Revista de Investigações Constitucionais, Curitiba, vol. 2, n. 2, p. 31-62, maio/ago. 2015a. DOI: 10.5380/rinc.v2i2.44510.

RODRÍGUEZ-ARANA MUÑOZ, Jaime. Direito fundamental à boa Administração Pública. Trad. Daniel Wunder Hachem. Belo Horizonte: Fórum, 2012a.

RODRÍGUEZ-ARANA MUÑOZ, Jaime. El Derecho Administrativo ante la crisis (El Derecho Administrativo Social). $A \& C$ - Revista de Direito Administrativo \& Constitucional, Belo Horizonte, ano 15, n. 60, p. 13-37, abr.jun. 2015b.

RODRÍGUEZ-ARANA MUÑOZ, Jaime. El derecho fundamental a la 
buena administración en la Constitución española y en la Unión Europea. $A \& C-$ Revista de Direito Administrativo \& Constitucional, Belo Horizonte, n. 40, pp. 117-149, abr./jun. 2010.

RODRÍGUEZ-ARANA MUÑOZ, Jaime. El derecho fundamental al buen gobierno y a la buena administración de instituciones públicas. Revista de Estudios Locales (CUNAL), Madrid, n. 100, pp. 39-47, abr. 2007.

RODRÍGUEZ-ARANA MUÑOZ, Jaime. Interés general, Derecho Administrativo y Estado de bienestar. Madrid: Iustel, 2012b.

RODRÍGUEZ-ARANA MUÑOZ, Jaime. Sobre el derecho fundamental a la buena administración y la posición jurídica del ciudadano. $A \& C-$ Revista de Direito Administrativo \& Constitucional, Belo Horizonte n. 47, pp. 13-50, ene./mar. 2012c.

RODRIGUEZ-ARANA, Jaime. Aproximación al derecho administrativo constitucional. Bogotá: Editora Universidad Externado, 2009.

RODRIGUEZ-ARANA, Jaime. La buena administración como principio y como derecho fundamental en Europa. Misión Jurídica. Revista de Derecho y Ciencias Sociales, Bogotá, n. 6, pp. 23-56, 2013.

SCHIAVI, Pablo. Información pública en clave de neoconstitucionalismo. $A \& C-$ Revista de Direito Administrativo \& Constitucional, Belo Horizonte, ano 14, n. 57, p. 13-45, jul./set. 2014.

SCHIAVI, Pablo. Régimen jurídico de la acción de acceso a la información pública en el Uruguay. Revista de Investigações Constitucionais, Curitiba, vol. 2, n. 2, p. 137-168, maio/ago. 2015.

SCHIER, Adriana da Costa Ricardo; MELO, Juliane Andrea de Mendes Hey. $\mathrm{O}$ direito à participação popular como expressão do Estado Social e Democrático de Direito. A\&C - Revista de Direito Administrativo \& Constitucional, Belo Horizonte, ano 17, n. 69, p. 127-147, jul./set. 2017.

SÖDERMAN, Jacob. El derecho fundamental a la buena administración. Gaceta Jurídica de la Unión Europea y de la Competencia, Madrid, n. 214, pp. 8-14, jul/ago. 2001.

TAMANAHA, Brian Z. Understanding Legal Pluralism: Past to present, 
local to global. Sydney Law Review, v. 30, pp. 375-411, 2008.

TOCQUEVILLE, Alexis de. El Antiguo Régimen y la Revolución. Introducción: José Enrique Rodríguez Ibáñez. Traducción: Angel Guillen. Madrid: Minerva, 2010.

UNIÓN EUROPEA. Parlamento Europeo, Consejo de Ministros y Comisión Europea. Carta de Derechos Fundamentales de la Unión Europea. 2000. Disponible en: <http://www.europarl.europa.eu/charter/ pdf/text_es.pdf $>$.

VALENCIA-TELLO, Diana Carolina. El Sistema de Control Interno y su complementariedad con el Sistema de Gestión de la Calidad. In: X Congreso Internacional del CLAD sobre la Reforma del Estado y la Administración Pública. Santiago de Chile, 2005.

VALIM, Rafael. El derecho fundamental de acceso a la información pública en el Derecho brasileño. Revista de Investigações Constitucionais, Curitiba, vol. 3, n. 1, p. 169-181, jan./abr. 2016.

WEBER, Max. Sociología del Poder. Los tipos de dominación. Edición y Traducción: Joaquin Abellán. Madrid: Alianza Editora, 2012.

WEIL, Prosper. O Direito Administrativo. Coimbra: Editora Almedina, 1977.

\section{Como citar este artigo (ABNT):}

TELLO, Diana Carolina Valencia; HACHEM, Daniel Wunder. La buena administración pública en el siglo XXI: análisis del caso colombiano. Veredas do Direito, Belo Horizonte, v. 15, n. 33, p. 101-130, set./dez. 2018. Disponível em: <http://www.domhelder.edu.br/revista/index.php/veredas/ article/view/1326>. Acesso em: dia mês. ano.

Artigo recebido em: 01/08/2018

Artigo aceito em: 07/12/2018 